\title{
Attention or Distraction? The Impact of Mobile Phone on Users' Psychological Well-Being
}

\author{
Jianxun Chu ${ }^{1}$, Sara Qaisar ${ }^{1 *}$, Zakir Shah ${ }^{2}$ and Afsheen Jalil ${ }^{3}$ \\ ${ }^{1}$ Department of Science and Technology Communication and Policy, University of Science and Technology of China, Hefei, \\ China, ${ }^{2}$ College of Media and International Culture, Zhejiang University, Hangzhou, China, ${ }^{3}$ Department of Technology \\ Management, International Islamic University, Islamabad, Pakistan
}

OPEN ACCESS

Edited by:

Gerrit C. Van Der Veer, University of Twente, Netherlands

Reviewed by: Amra Delic

University of Sarajevo, Bosnia and Herzegovina

José Baptista Coelho, University of Lisbon, Portugal

*Correspondence: Sara Qaisar saraqaisar@mail.ustc.edu.cn

Specialty section:

This article was submitted to Human-Media Interaction, a section of the journal Frontiers in Psychology

Received: 30 September 2020 Accepted: 05 February 2021 Published: 20 April 2021

Citation:

Chu J, Qaisar S, Shah Z and Jalil A (2021) Attention or Distraction? The Impact of Mobile Phone on Users

Psychological Well-Being

Front. Psychol. 12:612127. doi: 10.3389/fpsyg.2021.612127
Cumulative evidence has demonstrated that mobile phone distraction, in particular among emerging adults, is a growing problem. Considerable efforts have been made to contribute to the literature by proposing cognitive emotion pre-occupation which acts as an underlying mechanism through which mobile phone distraction results in a reduction in psychological well-being. The proposed model is supported by distraction-conflict theory which reveals that users, with high attention control, are better at coping with the negative consequences of mobile phone distraction. The data, consisting of 914 University students in China, was analyzed using statistical tools. The results support that mobile phone distraction has a significant positive relationship with cognitive emotional pre-occupation which negatively affects users' psychological well-being. Our findings also reveal that attention control moderated the mediation effect of cognitive emotional pre-occupation in association with mobile phone distraction and psychological well-being. The theoretical and practical implications are also discussed along with limitations and future research.

Keywords: mobile phone, distraction, attention control, cognitive emotional pre-occupation, psychological well-being

\section{INTRODUCTION}

Mobile phone technology has become a major part of people's daily life. People, especially youths use mobile technology for various purposes (Soyemi Jumoke, 2015; Alalwan et al., 2018). Mobile phone manufacturers offer new features and functionalities that have compelled users to use them (Zheng and Lee, 2016). The versatility of the mobile phone allows seamless integration of work, fun, social interaction, and enhances the quality of life in many ways (Zhang and Adipat, 2005; David et al., 2015; Longstreet and Brooks, 2017). According to the report generated by the China Internet Network Information center in 2019, 98.6\% of internet users in China had access to the internet via mobile devices in 2018-1.1\% higher than a year earlier. People aged between 10 and 39 years accounted for $67.8 \%$ of all internet users in China, where students $(25.4 \%)$ were the largest user group (CNNIC, 2019). In China, young adolescents are very fond of using a mobile phone in their daily routine activities such as during working, driving, and studying making it their first priority (Zhou, 2019), however, the negative consequences of the continuous usage of a mobile phone have been illustrated in recent studies. For example, the overuse of mobile phones has adverse effect on users' academic performance (Thomée et al., 2011; Lepp et al., 2015; Anderson et al., 2017), and work performance (Turel et al., 2011) and also cause technology driven consequences (e.g., distraction) (Coursaris et al., 2012). The problematic use of a mobile phone has become a societal debate; therefore, it is important to investigate the negative consequences of mobile phone usage in 
China. One of the reasons for the negative consequences of mobile phone technology is distraction (Sobhani and Farooq, 2018).

Mobile phone distraction (MD) is defined as the prevention of giving full attention to the nearest surroundings (David et al., 2015). The cognitive demand related to phone calls, email, texting, playing games, browsing, and social networking sites on mobile phones grabs user's attention or moves their attention away from other things so that they are not be able to focus on work-related activities. The mobile phone limits the user's attention and to make appropriate timely decisions and ultimately affects their psychological well-being (Salehan and Negahban, 2013). Psychological well-being is described as the overall psychological effectiveness of an individual (Gechman and Wiener, 1975; Sekaran, 1985). It measures the hedonic or pleasant aspect of individual feelings (Russell, 1980). Researchers have started analyzing the dark side of excessive mobile phone use on psychological well-being such a stress, depression, anxiety, and sleep disturbance (Bianchi and Phillips, 2005; Thomée et al., 2011; Nawaz et al., 2018). Many studies have focused on exploring the nature, measurement, and dimensions of the excessive use of technology (Chesley, 2005; Porter and Kakabadse, 2006; Thomée et al., 2007; Sahin and Çoklar, 2009; Choi and Lim, 2016). While many other research studies have investigated the cognitive and behavioral interconnections, particularly regarding negative consequences of mobile devices (Thomée et al., 2011; Turel et al., 2011; Turel and Serenko, 2012; Salehan and Negahban, 2013; Luqman et al., 2017; Cao et al., 2018; Volkmer, 2019).

Recent research studies have analyzed the impact of mobile phone distraction on social media use at work (Mark et al., 2018), during studying (David et al., 2015) and also its impact on memory and cognition (Craik, 2014). However, the negative consequences of mobile phone distraction have not been fully addressed in these previous studies. Due to an existing gap in previous research, it is important to study the negative consequences of mobile phone distraction.

This research study aims to examine how mobile phone distraction stimulates cognitive emotional pre-occupation which ultimately affect users' psychological well-being. Meanwhile, individuals' attentional control helps to enhance their psychological well-being (Ellis et al., 2014). Attention control refers to an individual's ability to focus only on those stimuli relevant to the current goal, minimizing the extent to which bottom-up influences capture our attention (Buschman and Miller, 2007). A few researchers have suggested that attention plays a critical role in reducing cognitive processing information by focusing and concentrating on the main objective (Wolfe et al., 2004; Buschman and Miller, 2007). Therefore, this study examines how attention control moderates the association between mobile phone distraction, cognitive emotional pre-occupation, and psychological well-being.

This study involves four main objectives intended to make both theoretical and practical contributions to the existing literature. First, the study examines the impact of mobile phone distraction on users' psychological well-being using distractionconflict theory. Second, the study examines how users' cognitive emotional pre-occupation mediates the relationships between mobile phone distraction and psychological well-being. Third, the current study analyzes the moderating effect of attention control on the association between mobile phone distraction and cognitive emotional pre-occupation of users. Finally, the study examines whether attention control moderate the mediating effect of cognitive emotional pre-occupation between mobile phone distraction and psychological well-being.

\section{THEORETICAL BACKGROUND AND HYPOTHESIS DEVELOPMENT}

\section{Distraction-Conflict Theory}

According to Leung (2015), a distraction is something that makes it hard for one to think or pay attention. It is a process by which an individual or group is distracted from the desired focus area, blocking, or reducing the desired information. Robert Baron's theory of distraction-conflict based on the idea that being aware of another object creates a conflict between attending to that object and attending to the task at hand (Baron, 1986). Similarly, the distraction conflict model has three major steps (I) Others distract, (II) distraction causes attention to conflict, and (III) attention conflict elevates stress (Nicholson et al., 2005). In the presence of others, there is a conflict between the object of attention and attending to the task that causes attention conflict (Baron et al., 1978). Attention conflict refers to the situation in which the person feels a strong urge, desire, or obligation to pay attention to the distractor (i.e., mobile phone) during performing their tasks, especially when the distractor is attention-grabbing and difficult to ignore (Baron, 1986). To be able to participate in more than one stimulus at a time, a person needs greater mental activity in the working memory of an individual (Sweller, 1988, 1994), known as a cognitive load (Grieve et al., 2014). Increased cognitive load can have negative effects by decreasing the attention, precision, working memory, and effectiveness of the individual (Coursaris et al., 2012) which can in turn increase stress (Sanders and Baron, 1975). Previous studies on stress examined that stress induced by the use of technology affect user's psychological well-being (Ayyagari et al., 2011; Thomée et al., 2011; Choi and Lim, 2016).

Distraction is due to a lack of attention; the absence of interest in the topic; and the great intensity, novelty or attraction of something other than the object of interest (Craik, 2014). It comes from both internal and external sources (Nicholson et al., 2005). External distractions include factors like visual triggers, social interactions, music, text messages, and telephone calls. While internal distractions include hunger, tiredness, illness, anxiety, and daydreaming. The interference of focus is supported by both external and internal distractions (Schumm and Post, 1997). Distraction-conflict theory provides insight into the evaluation of social media as "other" technology that distracts people from their primary goal (Leung, 2015). Negative consequences of distraction include effort difficulties and mental attention (Baecker et al., 1995) and impaired task performance (Cellier and Eyrolle, 1992; Suh et al., 1996).

Concerning mobile phones, its ubiquity and easy access makes it a potentially strong mechanism for distraction (David 
et al., 2015). Mobile phone distractions can be initiated by sound (when a user gets a message or call) or by sight (when receiving a notification from social networking site posts, online notifications of friends and family available on social networking sites) (Brooks, 2015). Users wonder what their friends and family are doing on social networking sites, scrolling and commenting on friend and family moments, sending videos and pictures, playing games, watching videos, online shopping, and listening to music only to engage themselves in mobile phone activities ( $\mathrm{Wu}$ et al., 2018). Therefore, the mobile phone has made distraction easier, due to their portability and the diversity of entertaining features. Even when users are doing work activities and studying (Thomée et al., 2011; Zhou, 2019), their primary focus is distracted by mobile phone technology (Coursaris et al., 2012). Therefore, the current study aims to test a proposed research model based on distraction-conflict theory to expand theoretical knowledge about whether and how mobile distraction, cognitive emotional pre-occupation and attention control affects users' psychological well-being.

\section{Mobile Phone Distraction and Cognitive Emotional Pre-occupation}

The use of mobile phone technology can lead to sacrificing other goals such as neglecting other commitments and a decrease in social activities with friends and family (Lin, 2019). The increased use of mobile phone technology in the daily life developed user's checking habits whereby they constantly make a brief inspection of their mobile phone applications (Porter and Kakabadse, 2006; Yang et al., 2016). It diverts the user's attention to non-workrelated activities (Ou and Davison, 2011; Rosen et al., 2013; Ziegler et al., 2018).

The diversity of mobile phone features and functions induce excessive usage behavior (Oulasvirta et al., 2012) and users experience difficulty in controlling the time they spend on the device and are easily distracted (Bianchi and Phillips, 2005). Such distraction stimulates cognitive emotional pre-occupation with behavior (King et al., 2013). Cognitive emotional pre-occupation is defined as "obsessive thought patterns involving technology use" (Caplan and High, 2006).

Pre-occupation with a behavior produces strong cravings to engage in the behavior which leads to problematic behavior (Collins and Lapp, 1992). Users with excessive usage behavior, develop a strong link in their long-term memory and their behavioral tendencies are associated with their reactions (Strack and Deutsch, 2004). The existing literature about addiction or pathologic use tends to consider cognitive emotional preoccupation as one of the core symptoms of problematic technology use (Nicholson et al., 2005). Cognitive emotional pre-occupation with mobile phone technology creates a strong willingness to use, which a mobile user may find difficult to endure and therefore, can act as a source for unplanned and even problematic use of the mobile phone (Cao et al., 2018). With the use of a mobile phone, an increased level of pre-occupation develops strong thoughts and emotional attachments, and the users feel a powerful urge to use even in a dangerous situation, where it is banned such as when driving a vehicle (Telemaque and Madueke, 2015; Turel and Bechara, 2016). Therefore, we hypothesized that

H1: Mobile phone distraction is positively related to cognitive emotional pre-occupation.

The diverse features of mobile phones increase the cognitive demand of users to use it. Such cognitive demand causes cognitive distraction. Cognitive distraction is defined as the user's difficulty to process two or more types of information at the same time (David et al., 2015). Phone calls, texting, and social media networking sites may cause a lapse in attention and concentration.

Previous research found that on-going use of mobile phone technology causes psychological distress (Chesley, 2005; Błachnio et al., 2013). Users expect enjoyment from the utilization of mobile phone technology but the loss of control on mobile phone usage affects cognitive limits and induces negative emotions. Previous research studies have found that mobile phone usage is negatively related to the concept of well-being, mood and anxiety disorder, fatigue, and mental health symptoms such as depression and sleep disturbance (Thomée et al., 2007, 2011; Dhir et al., 2018; Lin, 2019). Therefore, we hypothesized that

H2: Mobile phone distraction has a significant negative relationship with psychological well- being.

\section{Cognitive Emotional Pre-occupation and Psychological Well-Being}

Excessive use of a mobile phone leads to a reduction in the daily working routine, productivity, physical health, social relationships, and emotional well-being (Horwood and Anglim, 2018). A recent study explored how the excessive use of a mobile phone induces stress (Zheng and Lee, 2016). The continuous use, news and information, demands for attention from social networking sites, work activities and several forms of entertainment results in cognitive emotional pre-occupation (Lee et al., 2014). Cognitive emotional pre-occupation develops clusters in the long-term memory of the users (Strack and Deutsch, 2004). These clusters have strong impulses on behavior such as cognitive or emotional reactions (Craik, 2014). The pre-occupation can be disturbing because, in the presence of such pre-occupying ideas and feelings, individuals find it hard to concentrate on other tasks (Fillmore, 2001). These negative emotions weaken psychological well-being and eventually lead to disregarding essential elements of a user's life such as their family, education, and work (Choi and Lim, 2016). Therefore, we hypothesized that

H3: Cognitive emotional pre-occupation is negatively related to psychological well-being.

\section{Cognitive Emotional Pre-occupation as a Mediator}

We expected that cognitive emotion pre-occupation performs a mediating role in the relationship of mobile phone distraction and psychological well-being for the following reasons. First, mobile phone distraction causes excessive use which generates 
emotional and cognitive pre-occupation with behaviors (Cao et al., 2018). Such behaviors cause a strong desire to use a mobile phone to develop, which is difficult to resist (Zheng and Lee, 2016). This increased use of the mobile phone causes strong thoughts and emotional attachment to develop, leading to depression, which ultimately causes their wellbeing to deteriorate (Lee et al., 2014; Zhou, 2019). Second, previous studies have conceptualized that mobile phone users are extensively pre-occupied or "addicted" and overwhelmed with information, which reduces their cognitive capacity to manage the information effectively (Eppler and Mengis, 2004). When the user's cognitive limit exceeds the optimum level of technology utilization it may result in negative consequences (Ahuja et al., 2007). A previous study showed that mobile phone usage is negatively related to the concept of well-being that leads to interpersonal problems (Griffiths, 2005). Third, a compulsive desire to use the mobile phone can result in negative emotions such as emotional exhaustion, fatigue, and anxiety which affects their health and social relationships (Merrill and Liang, 2019). Such emotions reduce the psychological well-being of the users (Dhir et al., 2018). Therefore, we hypothesized that

$$
\begin{aligned}
& \text { H4: Cognitive emotional pre-occupation mediates } \\
& \text { the relationship of mobile phone distraction and } \\
& \text { psychological well-being. }
\end{aligned}
$$

\section{Attention Control as a Moderator}

Mobile phones increase people's enjoyment and comfort by providing them with flexible access to information which can turn into excessive use of the mobile phone (Yang et al., 2016). Such activities distract users from their routine work and enhances the cognitive and behavioral intentions of the users. However, due to attentional conflict, mobile phone distraction can have significant implications, ranging from short-term inconvenience (e.g., annoyance) to life-threatening circumstances such as motor accidents (Turel and Bechara, 2016). According to Ellis et al. (2014) and $\mathrm{Hu}$ et al. (2017) the ability to control attention switching and maintaining the negative affective response effect is known as attention control (AC). Some researchers suggest that individual differences in working memory capacity represent a different attention control on the use of working memory resources (Engle, 2002; Fukuda and Vogel, 2011). Attention control such as self- regulation ability, starting, maintaining concentration, and shifting internal and external attention to ensure flexibility is used to remain focused (Chambers et al., 2008). According to Derakshan and Eysenck (2009), attention control helps to increase processing efficiency and cognitive performance of an individual plays a critical role in decreasing data processing complexity and focusing on the concentrated goal. Therefore, this study uses attention control that helps to reduce the negative consequences of mobile phone distraction, because it may influence the capacity to neglect adverse cognitive and emotional consequences. Furthermore, evidence shows that distraction due to mobile phones has an impact on user's behavior (Craik, 2014). According to Cao et al. (2018) cognitive emotional pre-occupation produces problematic behavior which can affect psychological well-being.
Moreover, attention control helps to reduce depressive disorder (Hu et al., 2017). Thus, the study suggested that mobile phone distraction influences user's cognitive emotional behavior and affects their psychological well-being. The indirect relationship weakens when users have high attention control. Therefore, we hypothesized that

H5: Attention control moderates the effect of mobile phone distraction and cognitive emotional pre-occupation the weaker the relationship with high attention control.

H6: Attention control moderates the mediating effect of cognitive emotional pre-occupation between mobile phone distraction and psychological well-being.

Figure 1 shows the proposed theoretical framework.

\section{METHODOLOGY}

\section{Sample and Data Collection}

To examine the reliability and validity of the construct, a pilot study was conducted before the data collection process. The questionnaire was distributed online to 50 volunteer students in a large University in China. We performed exploratory factor analysis to ensure the reliability and validity of the construct. On the basis of findings, two items were removed from the revised final questionnaire. Empirical data were collected online by sharing the link of the questionnaire amongst social groups of University students (WeChat, Weibo and QQ) and by sending invitations to students via University email. The targeted sample involved students from a large University in China. This sample is suitable considering that the younger generation make up the majority of active users as they constitute the main body of mobile phone users. Therefore, students are considered as an adequate source of data for this study. Compeau et al. (2012) validated that University students represent part of the population, and their characteristics are similar to population characteristics. According to Kuss et al. (2013), students are more prone than others to present problematic online technology usage behavior. To ensure the quality of records we asked students to fill their student ID number in questionnaire so that repetition and redundancy of records will be removed. All participants were assured that their data will remain confidential and that it was collected for research purposes only. A convenience sampling technique was used to collect the data. A back-translation method was employed because the original questionnaire items were developed in English. Thus, the items were translated into Chinese by a Chinese translator for the data collection process and were subsequently converted back into English for further analysis (Brislin, 1970). The sample size was calculated by using the Godden (2004) formula for an infinite population (recommended sample was 384). A total of 935 survey responses were collected. After outliers and incomplete responses were eliminated, a total of 914 responses were gathered for further analysis.

\section{Measures}

We adapted the questionnaire from the literature and some items were modified according to the context of the current study. All 
TABLE 1 | Descriptive statistics of respondent characteristics.

\begin{tabular}{llcc}
\hline Measure & Value & Frequency & Percentage (\%) \\
\hline Gender & Male & 440 & 48.1 \\
Age (Years) & Female & 474 & 51.9 \\
& Below 18 & 2 & 0.2 \\
& $18-22$ & 84 & 9.2 \\
& $23-27$ & 266 & 29.1 \\
& $28-32$ & 416 & 45.5 \\
The frequency of mobile & Many times a day & 128 & 14.0 \\
phone use & Ab-42 & 14 & 1.5 \\
& Hourly & 404 & 0.4 \\
& Once a day & 254 & 55.1 \\
& Less than once a day & 62 & 27.8 \\
& & & 6.3 \\
\hline
\end{tabular}

items were measured using a 5-point Likert scale ranging from $1=$ strongly agree to $5=$ strongly disagree. The measurement items of all variables were described in Table 2. The demographic variables such as age, gender, and frequency of use were measured as control variables.

\section{Mobile Phone Distraction}

Mobile phone distraction was assessed using a four-items construct and it was adapted from Davis et al. (2002). The items represent the frequent use of a mobile phone while performing other activities. The Cronbach's alpha (CA) value is 0.95 .

\section{Cognitive Emotional Pre-occupation}

Cognitive emotional pre-occupation was measured using a sixitems scale and was adapted from Caplan and High (2006) and Zheng and Lee (2016). The items represent the feeling of an urge and thoughts to use a mobile phone when not using it for some time. The CA value is 0.95 .

\section{Psychological Well-Being}

Psychological well-being was measured using an eight-items scale that was adapted from Steinfield et al. (2008) and Choi and Lim (2016). The items consist of positive and negative wording, negative items were reverse coded to measure the psychological well-being. The CA value is 0.96 .

\section{Attention Control}

An eight-items scale was adapted from Farmer and Sundberg (1986) and Brooks (2015) to measure attention control. The items represent frequent shifting of attention during distraction and focusing on the main task. Some items were reverse coded to measure the positive effects of attention control. The CA value is 0.97 .

\section{DATA ANALYSIS AND RESULTS}

For data analysis, we used IBM-SPSS 22, IBM-AMOS 23, and Process macro by Hayes.
First, we performed the descriptive analysis to measure the demographic data. The demographic data of 914 students were based on males (48.1\%) and females (51.9\%). The remaining demographic data of 914 respondents are given in Table 1. Second, we performed exploratory factor analysis to measure the reliability and validity of the constructs. Third, we performed structural equation modeling (SEM) using IBM- AMOS 23 to find out the confirmatory factor analysis and model fit indices. Finally, we used Process macro in IBM-SPSS 22 to perform moderated-mediation analysis.

\section{Validity and Reliability of the Measurement Items}

Reliability pertains to the consistency of the construct, and validity pertains to how the constructs define the concept of the study (Carmines and Zeller, 1979). This study performed the exploratory factor analysis (EFA) using a principle component analysis with varimax rotation and a suppressed value of $<0.50$ to measure the validity of the construct. The results of the principle component analysis produced four factors with an Eigen value $>1$ explaining $83.26 \%$ of the total variance. All factor loadings on the expected factors are within the range of 0.81 to 0.93 (see Table 2) while the recommended values should exceed 0.7 to ensure construct validity (Hair et al., 1998). To measure the reliability of the constructs, we used $\mathrm{CA}$ and composite reliability (CR) values. The values of CA and CR must exceed the threshold of 0.7 (Anderson and Gerbing, 1988). Table 2 indicates that all CA and CR values exceed 0.7 , thereby ensuring measurement reliability. We also checked the average variance extracted (AVE) for convergent validity. In our data, the average variance extracted values of constructs ranged from 0.74 to 0.80 , greater than the minimum threshold of 0.5 as recommended by Fornell and Larcker (1981) which indicates that the items satisfied the convergent validity requirements.

Discriminant validity is the square root of all AVE values greater than the off-diagonal correlations between the constructs. Table 3 shows that the value of the square root of AVE is greater than the correlation coefficient of the constructs, thereby indicating discriminant validity.

Furthermore, we used IBM AMOS 23 to conduct confirmatory factor analysis (CFA) for validating the measures. The value of CMIN/ $d f=2.75$, NFI $=0.98$, TLI $=0.96$, IFI $=$ $0.98, \mathrm{CFI}=0.97, \mathrm{RMSEA}=0.05$ indicated a valid model fit. The results indicated that the values are within the acceptable range as suggested by Hair et al. (1998). Therefore, the results show a valid model fit.

We performed the Harman's one-factor test to evaluate the extent of common method bias (Podsakoff et al., 2003) because all questions were answered by the same individual. In this test, the threat of common method bias is considered high if a single factor account for more than $50 \%$ of total variance (Harman, 1976). The results reveal that none of the factors dominate the explanation of the variance, in which the most influential factor accounts for $36.9 \%$ of the variance. Moreover, other evidence of a common method bias includes high correlations $(r>0.9)$ 
TABLE 2 | Confirmatory factor analysis, AVE and composite reliability.

\begin{tabular}{|c|c|c|c|c|c|c|}
\hline Variables & & Items & $\begin{array}{l}\text { Factor } \\
\text { loading }\end{array}$ & $\begin{array}{l}\text { Cronbach's } \\
\text { alpha }\end{array}$ & AVE & $C R$ \\
\hline \multirow[t]{3}{*}{ Mobile phone distraction } & MD1 & When I am using a mobile phone, I don't think about my work/tasks & 0.89 & & & \\
\hline & MD3 & I often use a mobile phone to avoid doing unpleasant things in my work/task & 0.87 & 0.95 & 0.76 & 0.92 \\
\hline & MD4 & I find that I use mobile phone when I have work to do & 0.87 & & & \\
\hline & CG2 & I would feel lost if I was unable to use mobile phone & 0.80 & & & \\
\hline & CG3 & $\begin{array}{l}\text { I think obsessively about using mobile phone applications when I am not } \\
\text { using them }\end{array}$ & 0.88 & 0.95 & 0.75 & 0.94 \\
\hline & CG4 & Do you find yourself unable to stop thinking about using mobile phone? & 0.89 & & & \\
\hline & CG5 & Is it hard to distract yourself from thinking about mobile phone? & 0.90 & & & \\
\hline & CG6 & Do thoughts about using mobile phone intrude into your daily activities? & 0.89 & & & \\
\hline & AT4 & $\begin{array}{l}\text { When trying to focus my attention, I have difficulty blocking out distracting } \\
\text { thoughts }\end{array}$ & 0.90 & 0.97 & 0.80 & 0.96 \\
\hline & AT5 & When I need to concentrate, I have trouble focusing my attention & 0.93 & & & \\
\hline & AT6 & When working on something, still get distracted by mobile phone & 0.89 & & & \\
\hline & AT7 & $\begin{array}{l}\text { Distracting thought comes to mind, easy for me to shift my attention away } \\
\text { from it }\end{array}$ & 0.90 & & & \\
\hline & AT8 & $\begin{array}{l}\text { When I am reading or studying, I am easily distracted if notifications appear on } \\
\text { mobile phone }\end{array}$ & 0.89 & & & \\
\hline \multirow[t]{3}{*}{ Psychological well-being } & PW1 & The demands of everyday life often get me down & 0.84 & 0.96 & 0.74 & 0.95 \\
\hline & PW2 & I am quite good at managing the many responsibilities of my daily life & 0.81 & & & \\
\hline & PW3 & I have difficulty arranging my life in a way that is satisfying to me & 0.84 & & & \\
\hline
\end{tabular}

TABLE 3 | Correlations, mean, and standard deviation.

\begin{tabular}{|c|c|c|c|c|c|c|c|}
\hline Sr. no & Variables & Mean & SD & 1 & 2 & 3 & 4 \\
\hline 1 & Mobile phone distraction (MD) & 3.8 & 1.018 & $(0.87)$ & & & \\
\hline 2 & Cognitive emotion pre-occupation (CG) & 4.1 & 0.772 & $0.298^{\star \star}$ & $(0.86)$ & & \\
\hline 3 & Attention control (AT) & 2.1 & 0.887 & $-0.472^{\star \star}$ & $-0.171^{\star \star}$ & $(0.89)$ & \\
\hline 4 & Psychological well-being (PW) & 4.1 & 0.834 & $0.234^{\star \star}$ & $0.450^{\star \star}$ & $-0.173^{\star \star}$ & $(0.86)$ \\
\hline
\end{tabular}

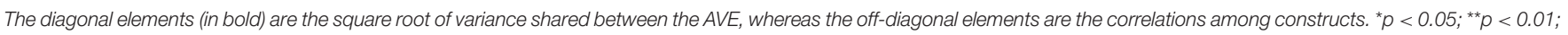
${ }^{\star \star \star} p<0.001$.

among variables (Pavlou and El Sawy, 2006). Table 3 shows that unusually high correlation in the sample is non-existing.

Thus, the common method bias is not a serious concern in this study.

\section{Structural Model}

Structural equation modeling (SEM) was used to measure the model fit indices. The results of model fit indices show that the model was a good fit $\left[\chi^{2}(666.752), d f=248, \chi^{2} / d f=2.68\right.$, NFI
$=0.96, \mathrm{IFI}=0.97, \mathrm{CFI}=0.97$ and $\mathrm{RMSEA}=0.06]$. The proposed model is within the acceptable range that is defined by Anderson and Gerbing (1988); in particular, $\chi^{2} / d f<5$, NFI $>0.90$, IFI $>$ 0.90, CFI $>0.90$ and RMSEA $<1.0$.

\section{Hypothesis Testing}

This study used structural equation modeling to test the direct and mediation hypothesis. The results of direct and indirect effects are given in Table 4. The relationship between mobile 
phone distraction and cognitive emotional pre-occupation ( $\beta$ $=0.29, p<0.001)$ was significant, leading to the acceptance of hypothesis 1 . The results indicate that the direct effect of mobile phone distraction and psychological well-being (without mediator) is significant $(\beta=-0.23, p<0.001)$, leading to the acceptance of hypothesis 2 . The relationship between the cognitive emotional pre-occupation and psychological well-being $(\beta=-0.35, p<0.001)$ was also significant, indicating the

TABLE 4 | Bootstrap results for direct and indirect effects.

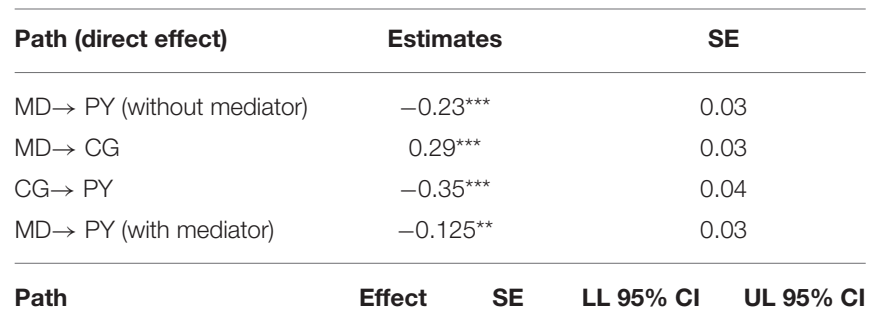

Indirect effect (bias corrected confidence interval method)

$\mathrm{MD} \rightarrow \mathrm{CG} \rightarrow \mathrm{PY} \quad-0.08^{\star *} \quad 0.021 \quad-0.134 \quad-0.050$

${ }^{\star \star} p<0.01,{ }^{\star \star \star} p<0.001, M D$, Mobile phone distraction; PY, psychological well-being; CG, cognitive emotional pre-occupation; LL, lower limit confidence interval; UL, upper limit confidence interval; SE, standard error. acceptance of hypothesis 3. The path diagram of SEM is demonstrated in Figure 2. We used the bootstrapping method with 5,000 bootstrap samples and a 95\% confidence interval for indirect effect. The bootstrapping result of the indirect effect of mobile phone distraction on psychological well-being via cognitive emotional pre-occupation is also significant $(\beta=$ $-0.08, p<0.01$ ). Hence, cognitive emotional pre-occupation partially mediates the relationship between mobile phone distraction and psychological well-being, thereby accepting hypothesis 4 . Regarding weak beta coefficient, previous studies have also identified weak beta value of indirect effect (Qian et al., 2017; Liu and Li, 2018). Furthermore, we used ANOVA to check the significant differences of control variables (gender, age, and frequency to use). The control variables exhibit insignificant effects on psychological well-being. Therefore, we exclude the control variables for further analysis.

\section{Moderated Mediation Analysis}

The moderated-mediation results are described in Table 5. The current study hypothesized a moderating role of attention control between mobile phone distraction and cognitive emotional preoccupation. We used model 7 of the Process macro by Hayes (2013) in IBM-SPSS 22 to analyze the moderated mediation analysis. Interestingly, the results showed that the relationship
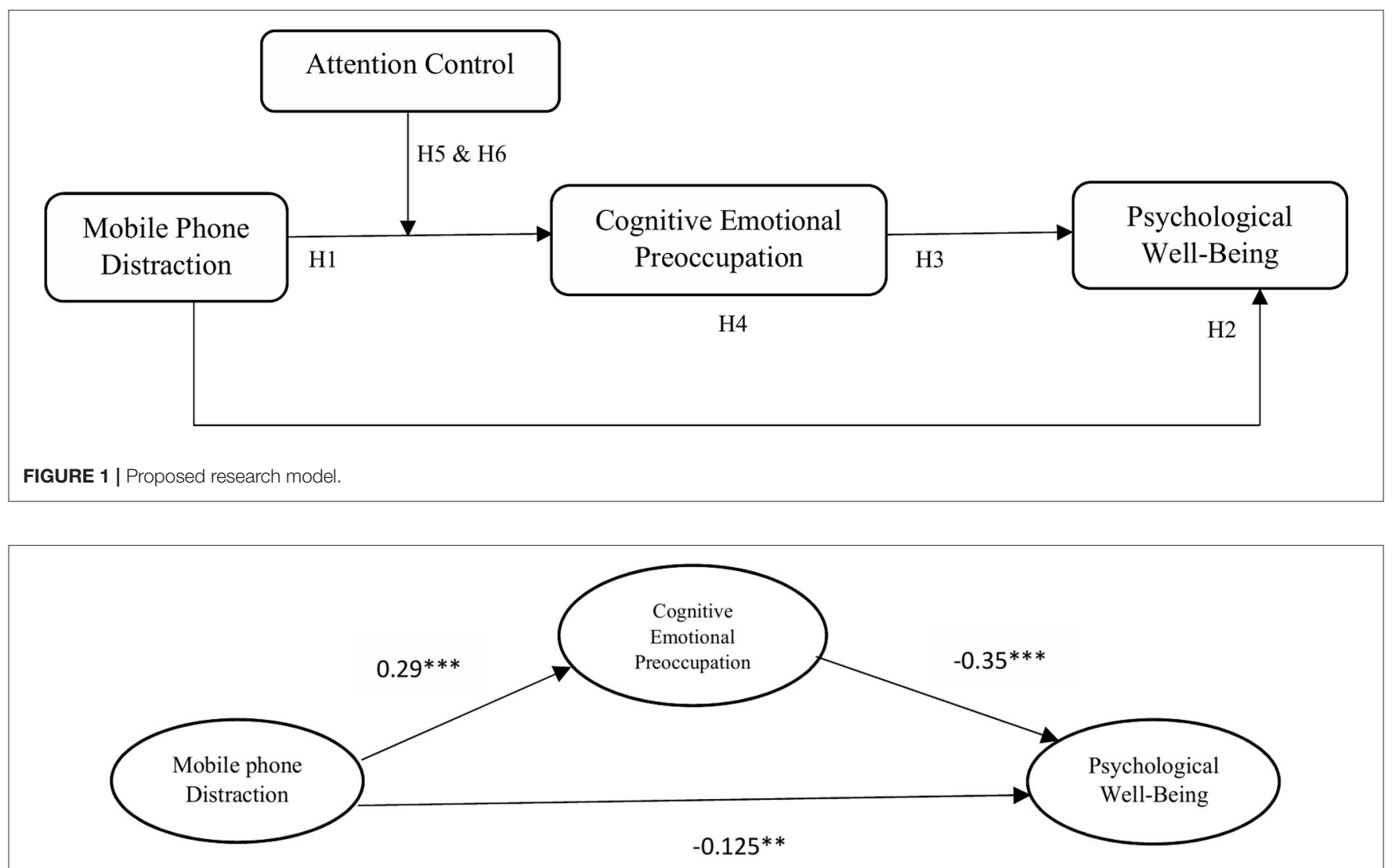

FIGURE 2 | SEM path diagram. 
between mobile phone distraction and cognitive emotional preoccupation is highly significant when attention control is low ( $\beta$ $=0.44, p<0.001$ ) but becomes weakest and insignificant when attention control is high $(\beta=0.05, p>0.05)$. Figure 3 shows the

TABLE 5 | Moderated mediation model of attention control, mobile phone distraction, cognitive emotional pre-occupation, and psychological well-being (model 7 process macro, $n=914$ ).

\begin{tabular}{|c|c|c|c|c|}
\hline & \multicolumn{2}{|c|}{$\begin{array}{c}\text { Cognitive } \\
\text { emotional pre-occupation }\end{array}$} & \multicolumn{2}{|c|}{$\begin{array}{l}\text { Psychological } \\
\text { well-being }\end{array}$} \\
\hline & $\beta$ & SE & $\beta$ & SE \\
\hline \multicolumn{5}{|c|}{ Explained variables } \\
\hline MD & $0.25^{\star \star \star}$ & 0.26 & $0.06^{\star \star \star}$ & 0.01 \\
\hline AT & $-0.07^{\star \star}$ & 0.29 & & \\
\hline CG & & & $0.301^{\star \star \star}$ & 0.02 \\
\hline $\mathrm{MD} \times \mathrm{AT}$ & $-0.222^{\star \star \star}$ & 0.02 & & \\
\hline \multirow[t]{2}{*}{ Levels of AT } & $\beta$ & SE & \multicolumn{2}{|c|}{$95 \% \mathrm{Cl}$} \\
\hline & & & LL & UL \\
\hline High $(+1 S D)$ & 0.447 & 0.03 & 0.3792 & 0.5166 \\
\hline Moderate & 0.2511 & 0.02 & 0.1998 & 0.3024 \\
\hline Low $(-1 S D)$ & 0.0543 & 0.03 & -0.0051 & 0.1136 \\
\hline \multicolumn{5}{|c|}{ Index of moderated mediation } \\
\hline & index $=-0.0711$ & $\mathrm{SE}=0.0103$ & $\mathrm{Cl}=[-\mathrm{C}$ & 7, -0.0516] \\
\hline
\end{tabular}

MD, mobile phone distraction; AT, attention control; CG, cognitive emotional preoccupation; $\mathrm{Cl}$, confidence interval; $L L$, lower limit; $U L$, upper limit. ${ }^{* *} p<0.01$, ${ }^{\star \star \star} p<0.001$ graphical presentation of moderating effect of attention control which describe that slop is becoming less positive as move from low to high attention control. Therefore, hypothesis 5 was supported and accepted.

Furthermore, the conditional indirect effect is reflected in the index of a moderated mediation analysis and if zero does not fall between the lower and upper limit of the $95 \%$ confidence interval then the indirect effect is conditional on the level of the moderator (Preacher and Hayes, 2008). The result of moderated mediation analysis [index $=-0.0711, \mathrm{SE}=$ $0.0103, \mathrm{CI}=(-0.0927,-0.0516)]$ shows that attention control fully moderated the mediation effect of cognitive emotion preoccupation between mobile phone distraction and psychological well-being, thereby accepting hypothesis 6 .

\section{DISCUSSION}

\section{Findings}

On the basis of distraction conflict theory, the current study proposed a research model to examine the effects of mobile phone distraction on psychological well-being. Specifically, the current study has the following aims. First, to examine the effect of mobile phone distraction and cognitive emotional preoccupation. Second, to investigate the impact of mobile phone distraction on psychological well-being. Third, to examine the mediating effect of cognitive emotional pre-occupation between mobile phone distraction and psychological well-being.

Finally, to study how attention control moderates the mediation effect of cognitive emotional pre-occupation between

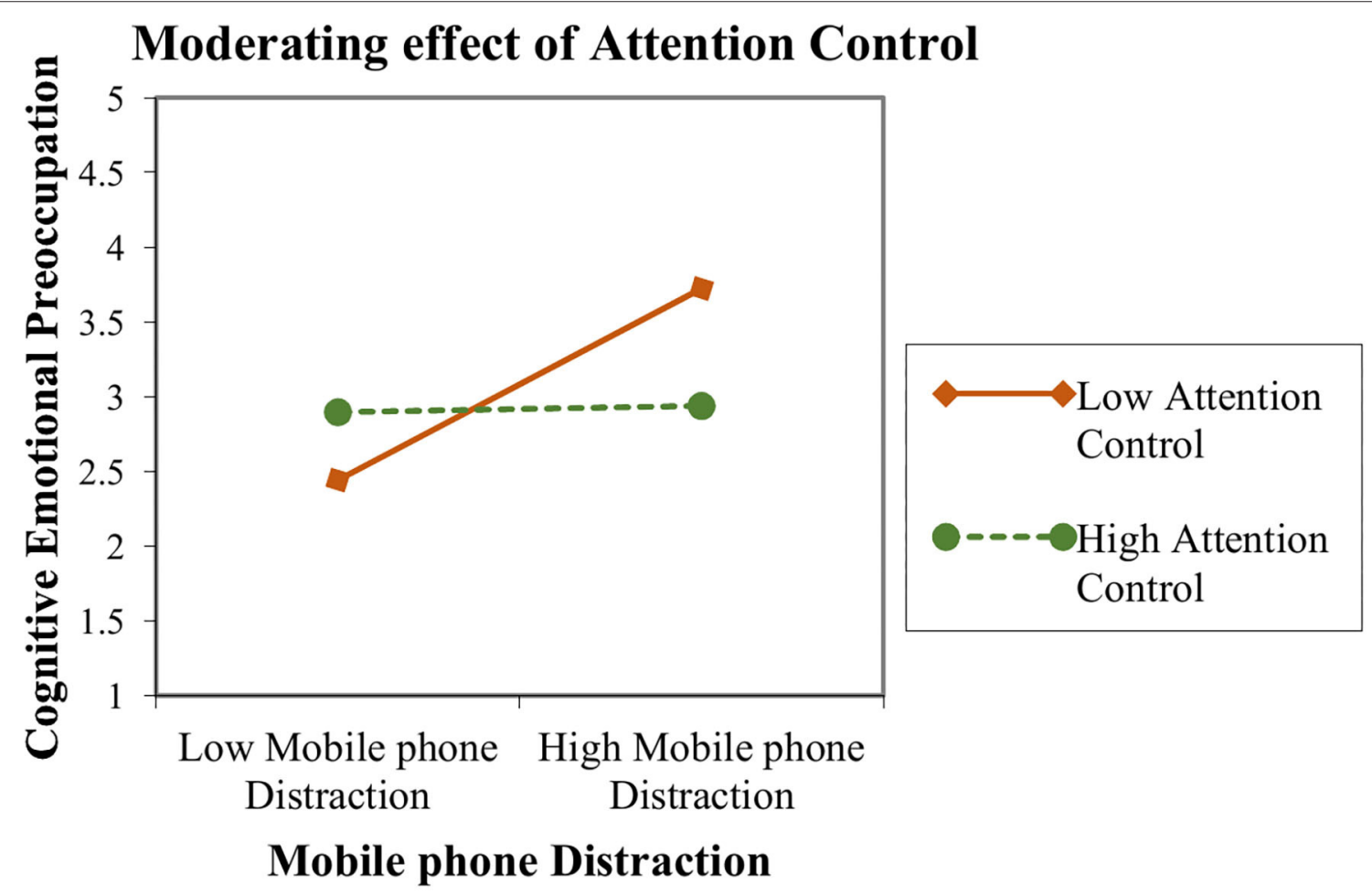

FIGURE 3 | Moderating effect of attention control between the relationship of mobile phone distraction and cognitive emotional pre-occupation. 
mobile phone distraction and psychological well-being. The key contribution of the current study is to examine mobile phone distraction in relation to attention control, cognitive emotional pre-occupation, and psychological well-being in China. The findings of the study support the proposed model and hypotheses and provides important theoretical and practical implications.

The current study resulted in several important findings. First, the current study contributes to the mobile phone distraction literature by identifying its consequences. Our result shows that mobile phone distraction exhibits a positive and significant relationship with cognitive emotional pre-occupation. Users have strong willingness to use mobile phone technology which causes strong emotional attachments to develop and users feel a powerful urge to use their mobile phone. Excessive use of mobile phone SNS is positively associated with cognitive emotional preoccupation of Chinese students (Cao et al., 2018). Similarly, Coursaris et al. (2012) and Longstreet and Brooks (2017) found that mobile phone distraction has an impact on the efficiency and effectiveness of users which in turn influence user's satisfaction and behavioral intention toward the usage of mobile phones. Moreover, Alalwan et al. (2018) and Leung (2015) revealed that mobile phone distraction has a positive relationship with perceived enjoyment and task performance.

Second, the excessive use of a mobile phone can result in lower psychological well-being. Our findings revealed that mobile phone distraction has a negative and significant association with psychological well-being. So much so that mobile phone usage limits the cognitive ability of the user so that they are not be able to focus on daily routine activities which leads to negative psychological well-being. Taiwanese students highly depend on mobile phone usage and perceive that being permanently connected to a mobile phone causes stress (Lin, 2019). Turel and Bechara (2016) found that mobile phone usage during driving distract users which ultimately has negative outcomes (e.g., accidents). Similarly, Schwebel et al. (2012) found that mobile phone distraction (e.g., talking on the phone, texting, and listening to music) has a negative impact on pedestrian behaviors.

Third, many scholars have found that an increase in use of a mobile phone can result in psychological consequences (e.g., anxiety, depression, fatigue, exhaustion) (Bianchi and Phillips, 2005; Thomée et al., 2011; Zheng and Lee, 2016). Excessive use of a mobile phone is positively related to mobile phone addiction, exerting a direct impact on psychological well-being in young Korean adults (Choi and Lim, 2016; Cha and Seo, 2018). Tangmunkongvorakul et al. (2019) shows that excessive use of a mobile phone has a negative effect on user's psychological well-being.

Similarly, Sahin and Çoklar (2009) and Dhir et al. (2018) found that compulsive use of a mobile phone increases fatigue and stress levels, and ultimately effects users' psychological wellbeing. Moreover, Cao et al. (2018) found that excessive use of a mobile phone causes cognitive-emotional pre-occupation which in turn has a positive relationship with psychological strains (e.g., life invasion, techno-exhaustion, and privacy invasion). Our findings show that cognitive emotional pre-occupation has a negative and significant relationship with psychological well-being. This study predicts that the concentration demand of social networking sites, text messages, calls, and other mobile features grab user attention, influencing their negative emotional reactions and behaviors and ultimately lowering users' psychological well-being.

Fourth, our findings show that cognitive emotional preoccupation partially mediate the relationship of mobile phone distraction and psychological well-being. Higher mobile phone use is associated with lower well-being (Volkmer, 2019). Similarly, users with high levels of cognitive emotional preoccupation with the internet will experience more negative outcomes (Caplan and High, 2006). Therefore, users who spend more time online are more likely to exhibit an increase in depression and social separation.

Finally, the study identified an important variable-attention control-which helps users to cope with the negative impact of mobile phone distraction and help to avoid getting emotionally connected. Our finding indicates that users with low attention control, experience more cognitive attachment and face attention conflicts with the mobile phone, whereas users with high attention control do not experience such an attachment and are more focused on their goals. The results are in line with the study of Hu et al. (2017) who suggested that attention control helps to reduce depressive disorder. Moreover, Derakshan and Eysenck (2009) and Jung et al. (2019) found that attention control helps to increase cognitive performance and efficiency, and improves the decision making process of individuals.

\section{Theoretical and Practical Implications}

This study exhibits certain important theoretical implications. First, the current study contributes to the existing literature on mobile phone distraction by examining the underlying mechanism through which mobile phone distraction affects psychological well-being. The study theoretically expands the etiology of problematic mobile phone use and discusses its potential adverse effect. The current study extends the literature on distraction-conflict theory by emphasizing that mobile phone distraction negatively affects psychological well-being. It also validates the distraction conflict theory by examining its validity on the mobile phone distraction and cognitive emotional behavior. Cognitive emotional pre-occupation is a new phenomenon in the field of mobile phone distraction. Second, the current research aims to enhance the understanding association of mobile phone distraction with cognitive emotion pre-occupation and its impact on psychological well- being. Finally, the study complements previous studies on attention control and contributes to the literature by examining the moderating effect of attention control in the association between mobile phone distraction, cognitive emotional pre-occupation, and psychological well-being which previous studies have not examined.

The current study has some practical implications. First, to avoid the negative consequences of mobile phone distractions, users must reduce their usage and manage their behaviors accordingly to overcome psychological issues. Second, the findings also have implications on policies where institutions must educate students about the negative psychological consequences of excessive use of a mobile phone so that they can reduce their usage while performing their routine work. Finally, this study also suggests that users with high attention 
control are not affected by the negative consequences of mobile phone distraction. Therefore, users should be more focused on their goals and limit the usage of a mobile phone to avoid negative consequences.

\section{Limitation and Future Research}

The current study had certain limitations. First, data was collected from University students which was the best fit for our research study. It is an empirical question as to whether the findings can be generalized to other countries and cultures. Various cultural factors, values, and beliefs have an impact of individual psychological well-being (Wissing and Temane, 2008; Grossi et al., 2012). Future research must focus on different target samples in other work settings or be conducted in a cross-cultural study of different countries to elucidate more interesting results. Particularly, researchers should focus on cultural factors such as gender, education and occupation to examine the effect of mobile phone distraction on psychological well-being. Second, the study focused on overall mobile phone distraction and was not specific to any mobile application such as social networking sites applications, mobile-gaming applications, etc. Future research must be focused on distraction caused by these applications to examine its effects on users' behavioral intentions. Third, the current study used control variables e.g., age, gender, and frequency of use, therefore, future research should use other control variables such as time and experience to find out more interesting results. Finally, the study considered the users' psychological well-being rather than focusing on specific psychological factors. Further investigation should extend this study to explore each factor of psychological well-being such as anxiety, sleep disorder and exhaustion, and should also examine its effect on physical and emotional well-being.

\section{Conclusion}

The current study was primarily focused on the implications of mobile phone distraction on psychological well-being. This study's greatest contribution was the finding that mobile phone distraction stimulates cognitive emotional pre-occupation

\section{REFERENCES}

Ahuja, M. K., Chudoba, K. M., Kacmar, C. J., McKnight, D. H., and George, J. F. (2007). IT road warriors: balancing work-family conflict, job autonomy, and work overload to mitigate turnover intentions. MIS Q. 31, 1-17. doi: $10.2307 / 25148778$

Alalwan, A. A., Baabdullah, A. M., Rana, N. P., Tamilmani, K., and Dwivedi, Y. K. (2018). Examining adoption of mobile internet in Saudi Arabia: extending TAM with perceived enjoyment, innovativeness and trust. Technol. Soc. 55, 100-110. doi: 10.1016/j.techsoc.2018.06.007

Anderson, E. L., Steen, E., and Stavropoulos, V. (2017). Internet use and problematic internet use: a systematic review of longitudinal research trends in adolescence and emergent adulthood. Int. J. Adolesc. Youth 22, 430-454. doi: 10.1080/02673843.2016.1227716

Anderson, J. C., and Gerbing, D. W. (1988). Structural equation modeling in practice: a review and recommended two-step approach. Psychol. Bull. 103, 411-423. doi: 10.1037/0033-2909.103.3.411

Ayyagari, R., Grover, V., and Purvis, R. (2011). Technostress: technological antecedents and implications. MIS Q. 35, 831-858. doi: 10.2307/41409963

Baecker, R. M., Grudin, J., Buxton, W. A. S., and Greenberg, S (eds.). (1995). Human-Computer Interaction: Toward the Year 2000. San Francisco, CA: Morgan Kaufmann Publishers Inc. with behavior and undermined user's psychological well-being. Moreover, users with high attention control, can easily manage their daily routine activities and ensure flexibility to remain focused. If the different factors proposed in the limitation of this study are included in future research, they could provide more interesting results of the negative functions of mobile phone usage.

\section{DATA AVAILABILITY STATEMENT}

The raw data supporting the conclusions of this article will be made available by the authors, without undue reservation.

\section{ETHICS STATEMENT}

Ethical review and approval was not required for the study on human participants in accordance with the local legislation and institutional requirements. Written informed consent from the participants was not required to participate in this study in accordance with the national legislation and the institutional requirements.

\section{AUTHOR CONTRIBUTIONS}

All authors listed have made a substantial, direct and intellectual contribution to the work, and approved it for publication.

\section{FUNDING}

This research was supported by National Science Foundation of China (NSFC No.71573241) and CAS-TWAS President's Fellowship Program.

\section{ACKNOWLEDGMENTS}

The authors would like to thank Dr. Muhammad Qaisar for his helpful comments and suggestions.

Baron, R. S. (1986). Distraction-Conflict theory: progress and problems. Adv. Exp Soc. Psychol. 19, 1-40. doi: 10.1016/S0065-2601(08)60211-7

Baron, R. S., Moore, D., and Sanders, G. S. (1978). Distraction as a source of drive in social facilitation research. J. Pers. Soc. Psychol. 36, 816-824. doi: 10.1037/0022-3514.36.8.816

Bianchi, A., and Phillips, J. G. (2005). Psychological Predictors of problem mobile phone use. Cyberpsychol. Behav. 8, 39-51. doi: 10.1089/cpb.2005.8.39

Błachnio, A., Przepiórka, A., and Rudnicka, P. (2013). psychological determinants of using facebook: a research review. Int. J. Human-Comput. Interact. 29, 775-787. doi: 10.1080/10447318.2013.780868

Brislin, R. W. (1970). Back-Translation for cross-cultural research. J. Cross-Cult. Psychol. 1, 185-216. doi: 10.1177/135910457000100301

Brooks, S. (2015). Does personal social media usage affect efficiency and well-being? Comput. Hum. Behav. 46, 26-37. doi: 10.1016/j.chb.2014. 12.053

Buschman, T. J., and Miller, E. K. (2007). Top-down versus bottom-up control of attention in the prefrontal and posterior parietal cortices. Science 315, 1860-1862. doi: 10.1126/science.1138071

Cao, X., Masood, A., Luqman, A., and Ali, A. (2018). Excessive use of mobile social networking sites and poor academic performance: antecedents and consequences from stressor-strain-outcome perspective. Comput. Hum. Behav. 85, 163-174. doi: 10.1016/j.chb.2018.03.023 
Caplan, S. E., and High, A. C. (2006). Beyond excessive use: the interaction between cognitive and behavioral symptoms of problematic internet use. Commun. Res. Rep. 23, 265-271. doi: 10.1080/08824090600962516

Carmines, E. G., and Zeller, R. A. (1979). Reliability and Validity Assessment. California City, CA:SAGE Publications. doi: 10.4135/9781412985642

Cellier, J.-M., and Eyrolle, H. (1992). Interference between switched tasks. Ergonomics 35, 25-36. doi: 10.1080/00140139208967795

Cha, S.-S., and Seo, B.-K. (2018). Smartphone use and smartphone addiction in middle school students in Korea: prevalence, social networking service, and game use. Health Psychol. Open 5:2055102918755046. doi: 10.1177/2055102918755046

Chambers, R., Lo, B. C. Y., and Allen, N. B. (2008). The impact of intensive mindfulness training on attentional control, cognitive style, and affect. Cogn. Ther. Res. 32, 303-322. doi: 10.1007/s10608-007-9119-0

Chesley, N. (2005). Blurring boundaries? Linking technology use, spillover, individual distress, and family satisfaction. J. Marriage Fam. 67, 1237-1248. doi: 10.1111/j.1741-3737.2005.00213.x

Choi, S. B., and Lim, M. S. (2016). Effects of social and technology overload on psychological well-being in young South Korean adults: the mediatory role of social network service addiction. Comput. Hum. Behav. 61, 245-254. doi: 10.1016/j.chb.2016.03.032

CNNIC (2019). Statistical Report on Internet Development in China. CNNIC. Available online at: http://www.cnnic.cn/hlwfzyj/hlwxzbg/hlwtjbg/201902/ P020190318523029756345.pdf (accessed June 27, 2019).

Collins, R. L., and Lapp, W. M. (1992). The temptation and restraint inventory for measuring drinking restraint. Br. J. Addict. 87, 625-633. doi: 10.1111/j.1360-0443.1992.tb01964.x

Compeau, D., Marcolin, B., Kelley, H., and Higgins, C. (2012). Research commentary-generalizability of information systems research using student subjects-a reflection on our practices and recommendations for future research. Inf. Syst. Res. 23, 1093-1109. doi: 10.1287/isre.1120.0423

Coursaris, C. K., Hassanein, K., Head, M. M., and Bontis, N. (2012). The impact of distractions on the usability and intention to use mobile devices for wireless data services. Comput. Hum. Behav. 28, 1439-1449. doi: 10.1016/j.chb.2012.03.006

Craik, F. I. M. (2014). Effects of distraction on memory and cognition: a commentary. Front. Psychol. 5:841. doi: 10.3389/fpsyg.2014.00841

David, P., Kim, J.-H., Brickman, J. S., Ran, W., and Curtis, C. M. (2015). Mobile phone distraction while studying. New Media Soc. 17, 1661-1679. doi: $10.1177 / 1461444814531692$

Davis, R. A., Flett, G. L., and Besser, A. (2002). Validation of a new scale for measuring problematic internet use: implications for pre-employment screening. Cyberpsychol. Behav. 5, 331-345. doi: 10.1089/109493102760275581

Derakshan, N., and Eysenck, M. W. (2009). Anxiety, processing efficiency, and cognitive performance: new developments from attentional control theory. Eur. Psychol. 14, 168-176. doi: 10.1027/1016-9040.14.2.168

Dhir, A., Yossatorn, Y., Kaur, P., and Chen, S. (2018). Online social media fatigue and psychological wellbeing-A study of compulsive use, fear of missing out, fatigue, anxiety and depression. Int. J. Inf. Manag. 40, 141-152. doi: $10.1016 /$ j.ijinfomgt.2018.01.012

Ellis, A. J., Wells, T. T., Vanderlind, W. M., and Beevers, C. G. (2014). The role of controlled attention on recall in major depression. Cogn. Emot. 28, 520-529. doi: 10.1080/02699931.2013.832153

Engle, R. W. (2002). Working memory capacity as executive attention. Curr. Dir. Psychol. Sci. 11, 19-23. doi: 10.1111/1467-8721.00160

Eppler, M. J., and Mengis, J. (2004). The concept of information overload: a review of literature from organization science, accounting, marketing, mis, and related disciplines. Inf. Soc. 20, 325-344. doi: 10.1080/01972240490507974

Farmer, R., and Sundberg, N. D. (1986). Boredom proneness-the development and correlates of a new scale. J. Pers. Assess. 50, 4-17. doi: 10.1207/s15327752jpa5001_2

Fillmore, M. T. (2001). Cognitive preoccupation with alcohol and binge drinking in college students: alcohol-induced priming of the motivation to drink. Psychol. Addict. Behav. 15, 325-332. doi: 10.1037/0893-164X.15.4.325

Fornell, C., and Larcker, D. F. (1981). Evaluating structural equation models with unobservable variables and measurement error. J. Mark. Res. 18, 39-50. doi: $10.1177 / 002224378101800104$

Fukuda, K., and Vogel, E. K. (2011). Individual differences in recovery time from attentional capture. Psychol. Sci. 22, 361-368. doi: 10.1177/0956797611398493
Gechman, A. S., and Wiener, Y. (1975). Job involvement and satisfaction as related to mental health and personal time devoted to Work. J. Appl. Psychol. 60, 521-523. doi: 10.1037/h0076902

Godden, B. (2004). Sample Size Formulas. Available at: http://www.williamgodden. com/samplesizeformula.pdf (accessed September 11, 2019).

Grieve, R., Witteveen, K., Tolan, G. A., and Jacobson, B. (2014). Development and validation of a measure of cognitive and behavioural social self-efficacy. Personal. Individ. Differ. 59, 71-76. doi: 10.1016/j.paid.2013.11.008

Griffiths, M. (2005). A 'components' model of addiction within a biopsychosocial framework. J. Subst. Use 10, 191-197. doi: 10.1080/14659890500114359

Grossi, E., Tavano Blessi, G., Sacco, P. L., and Buscema, M. (2012). The interaction between culture, health and psychological well-being: data mining from the italian culture and well-being project. J. Happiness Stud. 13, 129-148. doi: 10.1007/s10902-011-9254-x

Hair, J. F., Black, W. C., Babin, B. J., Anderson, R. E., and Tatham, R. L. (1998). Multivariate Data Analysis. Upper Saddle River, NJ: Prentice Hall.

Harman, H. H. (1976). Modern Factor Analysis, 3rd Edn. Chicago, IL: University of Chicago press.

Hayes, A. F. (2013). Introduction to Mediation, Moderation, and Conditional Process Analysis: A Regression-Based Approach. New York, NY: Guilford Press.

Horwood, S., and Anglim, J. (2018). Personality and problematic smartphone use: a facet-level analysis using the five factor model and HEXACO frameworks. Comput. Hum. Behav. 85, 349-359. doi: 10.1016/j.chb.2018.04.013

Hu, B., Rao, J., Li, X., Cao, T., Li, J., Majoe, D., et al. (2017). Emotion regulating attentional control abnormalities in major depressive disorder: an event-related potential study. Sci. Rep. 7:13530. doi: 10.1038/s41598-017-13626-3

Jung, K., Jeong, J., and Kralik, J. D. (2019). A computational model of attention control in multi-attribute, context-dependent decision making. Front. Comput. Neurosci. 13:40. doi: 10.3389/fncom.2019.00040

King, D. L., Haagsma, M. C., Delfabbro, P. H., Gradisar, M., and Griffiths, M. D. (2013). Toward a consensus definition of pathological video-gaming: a systematic review of psychometric assessment tools. Clin. Psychol. Rev. 33, 331-342. doi: 10.1016/j.cpr.2013.01.002

Kuss, D. J., Griffiths, M. D., and Binder, J. F. (2013). Internet addiction in students: prevalence and risk factors. Comput. Hum. Behav. 29, 959-966. doi: 10.1016/j.chb.2012.12.024

Lee, Y.-K., Chang, C.-T., Lin, Y., and Cheng, Z.-H. (2014). The dark side of smartphone usage: psychological traits, compulsive behavior and technostress. Comput. Hum. Behav. 31, 373-383. doi: 10.1016/j.chb.2013.10.047

Lepp, A., Barkley, J. E., and Karpinski, A. C. (2015). The relationship between cell phone use and academic performance in a sample of U.S. college students. SAGE Open 5:2158244015573169. doi: 10.1177/2158244015573169

Leung, K. (2015). The effect of distractions on task performance and enjoyment as moderated by regulatory fit (Master's theses), 4595. doi: 10.31979/etd.2kv f-5j6a

Lin, J.-H. T. (2019). Permanently online and permanently connected: taiwanese University students' attachment style, mobile phone usage, and well-being. Chin. J. Commun. 12, 44-65. doi: 10.1080/17544750.2018.1511606

Liu, H., and Li, G. (2018). Linking transformational leadership and knowledge sharing: the mediating roles of perceived team goal commitment and perceived team identification. Front. Psychol. 9:1331. doi: 10.3389/fpsyg.2018.01331

Longstreet, P., and Brooks, S. (2017). Life satisfaction: a key to managing internet \& social media addiction. Technol. Soc. 50, 73-77. doi: 10.1016/j.techsoc.2017.05.003

Luqman, A., Cao, X., Ali, A., Masood, A., and Yu, L. (2017). Empirical investigation of facebook discontinues usage intentions based on SOR paradigm. Comput. Hum. Behav. 70, 544-555. doi: 10.1016/j.chb.2017.01.020

Mark, G., Czerwinski, M., and Iqbal, S. T. (2018). "Effects of Individual Differences in Blocking Workplace Distractions," in Proceedings of the 2018 CHI Conference on Human Factors in Computing Systems - CHI '18 (Montreal QC: ACM Press), 1-12. doi: $10.1145 / 3173574.3173666$

Merrill, R. A., and Liang, X. (2019). Associations between adolescent media use, mental health, and risky sexual behaviors. Child. Youth Serv. Rev. 103, 1-9. doi: 10.1016/j.childyouth.2019.05.022

Nawaz, M. A., Shah, Z., Nawaz, A., Asmi, F., Hassan, Z., and Raza, J. (2018). Overload and exhaustion: classifying SNS discontinuance intentions. Cogent Psychol. 5, 1-18. doi: 10.1080/23311908.2018.1515584

Nicholson, D. B., Parboteeah, D. V., Nicholson, J. A., and Valacich, J. S. (2005). "Using distraction-conflict theory to measure the effects of distractions on 
individual task performance in a wireless mobile environment," in Proceedings of the 38th Annual Hawaii International Conference on System Sciences (Big Island, HI: IEEE), $33 \mathrm{c}-33 \mathrm{c}$.

Ou, C. X. J., and Davison, R. M. (2011). Interactive or interruptive? Instant messaging at work. Decis. Support Syst. 52, 61-72. doi: 10.1016/j.dss.2011.05.004

Oulasvirta, A., Rattenbury, T., Ma, L., and Raita, E. (2012). Habits make smartphone use more pervasive. Pers. Ubiquitous Comput. 16, 105-114. doi: 10.1007/s00779-011-0412-2

Pavlou, P. A., and El Sawy, O. A. (2006). From IT leveraging competence to competitive advantage in turbulent environments: the case of new product development. Inf. Syst. Res. 17, 198-227. doi: 10.1287/isre.1060.0094

Podsakoff, P. M., MacKenzie, S. B., Lee, J.-Y., and Podsakoff, N. P. (2003). Common method biases in behavioral research: a critical review of the literature and recommended remedies. J. Appl. Psychol. 88, 879-903. doi: 10.1037/0021-9010.88.5.879

Porter, G., and Kakabadse, N. K. (2006). HRM perspectives on addiction to technology and work. J. Manag. Dev. 25, 535-560. doi: 10.1108/02621710610670119

Preacher, K. J., and Hayes, A. F. (2008). Asymptotic and resampling strategies for assessing and comparing indirect effects in multiple mediator models. Behav. Res. Methods 40, 879-891. doi: 10.3758/BRM.40.3.879

Qian, J., Wang, B., Han, Z., and Song, B. (2017). Ethical leadership, leadermember exchange and feedback seeking: a double-moderated mediation model of emotional intelligence and work-unit structure. Front. Psychol. 8:1174. doi: 10.3389/fpsyg.2017.01174

Rosen, L. D., Mark Carrier, L., and Cheever, N. A. (2013). Facebook and texting made me do it: media-induced task-switching while studying. Comput. Hum. Behav. 29, 948-958. doi: 10.1016/j.chb.2012.12.001

Russell, J. A. (1980). A circumplex model of affect. J. Pers. Soc. Psychol. 39, 1161-1178. doi: 10.1037/h0077714

Sahin, Y. L., and Çoklar, A. N. (2009). Social networking users' views on technology and the determination of technostress levels. Procedia Soc. Behav. Sci. 1, 1437-1442. doi: 10.1016/j.sbspro.2009.01.253

Salehan, M., and Negahban, A. (2013). Social networking on smartphones: when mobile phones become addictive. Comput. Hum. Behav. 29, 2632-2639. doi: 10.1016/j.chb.2013.07.003

Sanders, G. S., and Baron, R. S. (1975). The motivating effects of distraction on task performance. J. Pers. Soc. Psychol. 32, 956-963. doi: 10.1037/0022-3514.32.6.956

Schumm, J. S., and Post, S. (1997). Executive learning: Successful strategies for college reading and studying. Prentice Hall.

Schwebel, D. C., Stavrinos, D., Byington, K. W., Davis, T., O’Neal, E. E., and de Jong, D. (2012). Distraction and pedestrian safety: how talking on the phone, texting, and listening to music impact crossing the street. Accid. Anal. Prev. 45, 266-271. doi: 10.1016/j.aap.2011.07.011

Sekaran, U. (1985). The paths to mental health: an exploratory study of husbands and wives in dual-career families. J. Occup. Psychol. 58, 129-137. doi: 10.1111/j.2044-8325.1985.tb00188.x

Sobhani, A., and Farooq, B. (2018). Impact of smartphone distraction on pedestrians' crossing behaviour: an application of head-mounted immersive virtual reality. Transp. Res. Part F-Traffic Psychol. Behav. 58, 228-241. doi: 10.1016/j.trf.2018.06.020

Soyemi Jumoke, O. S. (2015). Analysis of mobile phone impact on student academic performance in tertiary institution. IJETAE 5.

Steinfield, C., Ellison, N. B., and Lampe, C. (2008). Social capital, self-esteem, and use of online social network sites: a longitudinal analysis. J. Appl. Dev. Psychol. 434-45. doi: 10.1016/j.appdev.2008.07.002

Strack, F., and Deutsch, R. (2004). Reflective and impulsive determinants of social behavior. Personal. Soc. Psychol. Rev. 28, 220-247. doi: 10.1207/s15327957pspr0803_1

Suh, E., Diener, E., and Fujita, F. (1996). Events and subjective wellbeing: only recent events matter. J. Pers. Soc. Psychol. 70, 1091-1102. doi: 10.1037/0022-3514.70.5.1091

Sweller, J. (1988). Cognitive load during problem solving: effects on learning. Cogn. Sci. 12, 257-285. doi: 10.1207/s15516709cog1202_4

Sweller, J. (1994). Cognitive load theory, learning difficulty, and instructional design. Learn. Instr. 4, 295-312. doi: 10.1016/0959-4752(94)90003-5
Tangmunkongvorakul, A., Musumari, P. M., Thongpibul, K., Srithanaviboonchai, K., Techasrivichien, T., Suguimoto, S. P., et al. (2019). Association of excessive smartphone use with psychological well-being among University students in Chiang Mai, Thailand. PLoS ONE 14:e0210294. doi: 10.1371/journal.pone.0210294

Telemaque, J. H. R., and Madueke, C. Z. (2015). Cell phoning and texting while driving: multitasking ourselves to death. SAGE Open 5:2158244015595089. doi: 10.1177/2158244015595089

Thomée, S., Eklöf, M., Gustafsson, E., Nilsson, R., and Hagberg, M. (2007). Prevalence of perceived stress, symptoms of depression and sleep disturbances in relation to information and communication technology (ICT) use among young adults - an explorative prospective study. Comput. Hum. Behav. 23, 1300-1321. doi: 10.1016/j.chb.2004.12.007

Thomée, S., Härenstam, A., and Hagberg, M. (2011). Mobile phone use and stress, sleep disturbances, and symptoms of depression among young adults - a prospective cohort study. BMC Public Health 11:66. doi: $10.1186 / 1471-2458-11-66$

Turel, O., and Bechara, A. (2016). Social networking site use while driving: adhd and the mediating roles of stress, self-esteem and craving. Front. Psychol. 7:455. doi: 10.3389/fpsyg.2016.00455

Turel, O., and Serenko, A. (2012). The benefits and dangers of enjoyment with social networking websites. Eur. J. Inf. Syst. 21, 512-528. doi: $10.1057 /$ ejis.2012.1

Turel, O., Serenko, A., and Bontis, N. (2011). Family and work-related consequences of addiction to organizational pervasive technologies. Inf. Manage. 48, 88-95. doi: 10.1016/j.im.2011.01.004

Volkmer, S. A. (2019). Unhappy and addicted to your phone? - higher mobile phone use is associated with lower well-being. Comput. Hum. Behav. 93, 210-8. doi: 10.1016/j.chb.2018.12.015

Wissing, M., and Temane, Q. M. (2008). The structure of psychological well-being in cultural context: towards a hierarchical model of psychological health. J. Psychol. Afr. 18, 45-56. doi: 10.1080/14330237.2008. 10820170

Wolfe, J. M., Horowitz, T. S., Kenner, N., Hyle, M., and Vasan, N. (2004). How fast can you change your mind? The speed of top-down guidance in visual search. Vision Res. 44, 1411-1426. doi: 10.1016/j.visres.2003.11.024

Wu, M., Yang, C., Wang, C., Zhao, J. L., Wu, S., and Liang, L. (2018). "Distraction or connection? an investigation of social media use at work," in Proceedings of the 51st Hawaii International Conference on System Sciences. doi: 10.24251/HICSS.2018.125

Yang, S., Wang, B., and Lu, Y. (2016). Exploring the dual outcomes of mobile social networking service enjoyment: the roles of social self-efficacy and habit. Comput. Hum. Behav. 64, 486-496. doi: 10.1016/j.chb.2016.07.010

Zhang, D., and Adipat, B. (2005). Challenges, methodologies, and issues in the usability testing of mobile applications. Int. J. Hum. Computer Interact. 18, 293-308. doi: 10.1207/s15327590ijhc1803_3

Zheng, X., and Lee, M. K. O. (2016). Excessive use of mobile social networking sites: negative consequences on individuals. Comput. Hum. Behav. 65, 65-76. doi: $10.1016 /$ j.chb.2016.08.011

Zhou, B. (2019). Fear of missing out, feeling of acceleration, and being permanently online: a survey study of University students' use of mobile apps in China. Chin. J. Commun. 12, 66-83. doi: 10.1080/17544750.2018.1523803

Ziegler, D. A., Janowich, J. R., and Gazzaley, A. (2018). Differential impact of interference on internally- and externally-directed attention. Sci. Rep. 8:2498. doi: 10.1038/s41598-018-20498-8

Conflict of Interest: The authors declare that the research was conducted in the absence of any commercial or financial relationships that could be construed as a potential conflict of interest.

Copyright (c) 2021 Chu, Qaisar, Shah and Jalil. This is an open-access article distributed under the terms of the Creative Commons Attribution License (CC BY). The use, distribution or reproduction in other forums is permitted, provided the original author(s) and the copyright owner(s) are credited and that the original publication in this journal is cited, in accordance with accepted academic practice. No use, distribution or reproduction is permitted which does not comply with these terms. 